\title{
Editorial
}

\section{AN INTRODUCTION TO FRACTAL-BASED APPROACHES IN UNCONVENTIONAL RESERVOIRS — PART I}

\author{
JIANCHAO CAI,,${ }^{*} \|$ LIEHUI ZHANG,${ }^{\dagger}$ YANG JU ${ }^{\ddagger}$ GIORGIO PIA,$\S$ \\ and ZHIEN ZHANG $₫$ \\ ${ }^{*}$ Hubei Subsurface Multi-Scale Imaging Key Laboratory \\ Institute of Geophysics and Geomatics \\ China University of Geosciences \\ Wuhan 430074, P. R. China \\ ${ }^{\dagger}$ State Key Laboratory of Oil and Gas Reservoir Geology and Exploitation \\ Southwest Petroleum University \\ Chengdu, Sichuan 610500, P. R. China \\ ${ }^{\ddagger}$ State Key Laboratory of Coal Resources and Safe Mining \\ China University of Mining 85 Technology (Beijing) \\ Beijing 100083, P. R. China \\ $\S$ Dipartimento di Ingegneria Meccanica, Chimica e dei Materiali \\ Università degli Studi di Cagliari, Piazza d'Armi \\ 09123 Cagliari, Italy \\ "School of Chemistry and Chemical Engineering \\ Chongqing University of Technology \\ Chongqing 400054, P. R. China \\ "laijc@cug.edu.cn
}

Received March 28, 2018

Accepted April 4, 2018

Published April 16, 2018

\footnotetext{
"Corresponding author.

This is an Open Access article published by World Scientific Publishing Company. It is distributed under the terms of the Creative Commons Attribution 4.0 (CC-BY) License. Further distribution of this work is permitted, provided the original work is properly cited.
} 


\begin{abstract}
In recent years, unconventional reservoirs have drawn tremendous attention worldwide. This special issue collects a series of recent works on various fractal-based approaches in unconventional reservoirs. The topics covered in this introduction include fractal characterization of pore (throat) structure and its influences on the physical properties of unconventional rocks, fractal characteristics of crack propagation in coal and fluid flow in rock fracture network under shearing, porous flow phenomena and gas adsorption mechanism, fractal geophysical method in reservoirs.
\end{abstract}

Keywords: Fractal; Unconventional Reservoirs; Modeling.

\section{INTRODUCTION}

Unconventional reservoirs include shale oil and gas, tight oil and gas, coalbed methane, and natural gas hydrate, etc. In recent years, unconventional reservoirs have received a great deal of attention from reservoir engineers, geologists, geophysicists, physicists, and energy economists. Unconventional natural gas and oil systems have tremendous complex microstructure. A three-dimensional pore network modeling of tight sandstone with a porosity of 0.144 is depicted in Fig. 1. A better understanding of the nano- and micro-scale structures of these reservoir rocks, and their transport properties are critical for improving the efficiency of these natural oil and gas systems. Due to the complexity of unconventional rock microstructures, and the strong interactions

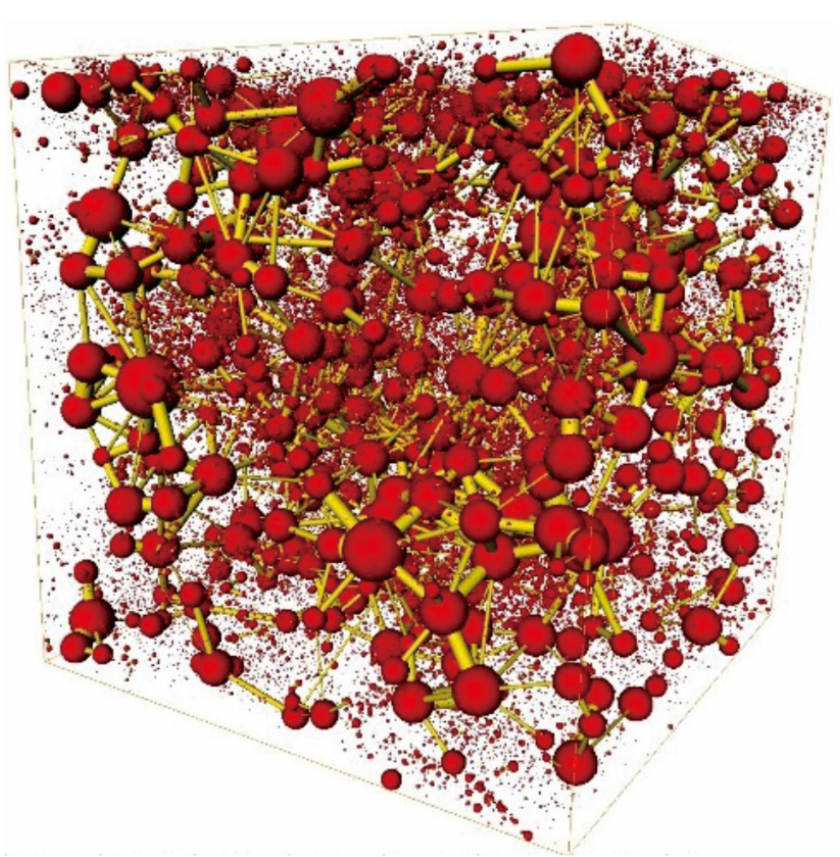

Fig. 1 Three-dimensional pore network modeling of tight sandstone. between fluids and pore surfaces due to the reduced dimensionality, conventional approaches and theories (equations) are typically not applicable to quantify and characterize fluid flow in these porous reservoir rocks.

Fractal geometry offers a quantitative evaluation on the heterogeneity and complexity of reservoir rocks, such as pore surface structure, pore size distribution and fracture networks, which significantly affects fluids flow and transport in these porous systems. 10 The fractal-based approaches have been widely and successfully used in unconventional reservoirs. This special issue emphasizes the fundamental innovations and gathers together a number of recent papers on new applications of fractal theory in unconventional reservoirs.

\section{OVERVIEW OF WORKS PRESENTED IN THIS SPECIAL ISSUE}

The papers published in this issue of Fractals represent Part I of a special topic covering fractal-based approaches in unconventional reservoirs. They can be clearly divided into the following four groups.

The first group of papers focuses on fractal theory applied to pore (throat) structure characterization and its influences on physical properties of rocks. Fractal dimension offers a quantitative evaluation on pore (throat) structure. In order to better understand the impact of fractal features of pore-throat structures on effective physical properties of tight gas sandstones, Huang et al! ${ }^{7}$ carried out a series of measurements and analyzed 20 sandstone samples of the Shihezi Formation from 16 wells of the Sulige Gas Field in the Ordos Basin, China. The fractal dimensions of pore-throat structures were calculated and its influences on the physical properties of sandstone samples were 
investigated. Combining low-pressure $\mathrm{N}_{2}$ adsorption and other technologies, fractal dimensions of pore surface with Frenkel-Halsey-Hill model were obtained to investigate the fractal characteristic of pores shale from Taiyuan formation by Kunjie Li et al. ${ }^{8}$ Yanchang Formation from the Ordos Basin by Yang Wang et al.,, 9 and Biyang Depression of Henan Oilfield by Jijun Li et al ${ }^{10}$ The controlling factors for fractal dimensions, including pore morphology, total organic carbon content, and mineral content, were analyzed accordingly. To compare the fractal characteristics between marine and continental shales, Liu et al 11 also characterized the reservoir properties and fractal dimensions of 18 shale samples. Weiming Wang et al. ${ }^{[12}$ studied the morphological characteristics and size distribution of nanoscale pores in the volcanic rocks of the Haerjiawu Formation using the results of low temperature nitrogen adsorption experiments and fractal geometry theory. Considering the relationship between the porosity of rocks and the fractal characteristics of pore structures, Lin et al $l^{[13}$ proposed a new improved image segmentation method, which used the calculated porosity of core images as a constraint to obtain the best threshold.

The second group of papers focuses on fractal characterization of fractal network and crack propagation. Huang et al. 14 studied the size effect on the permeability and shear induced flow anisotropy of fractal rock fractures. In their work, the effect of model size on fluid flow through fractal rough fractures under shearing was investigated using a numerical simulation method. The shear behavior of rough fractures with self-affine properties was described using an analytical model. Fluid flow through fractures in the directions both parallel and perpendicular to the shear directions was simulated by solving the Reynolds equation using a finite element code. Zhao et al ${ }^{[15}$ studied the fractal characteristics of crack propagation in coal containing beddings under the impact loading condition. The image processing method and fractal dimension calculation software were combined to further analyze the effects of bedding and loading rate on the fractal characteristics of crack propagation in coal.

The third group of papers focuses on the porous flow and gas adsorption mechanism by means of fractal geometry. Lei et al ${ }^{[16]}$ conducted laboratory tests on the stress-dependent relative permeability in porous media and developed a corresponding fractal model. The predictions from the proposed analytical model exhibited similar variation trends to the experimental data. Shen et al! ${ }^{17}$ established an analytic equation of spontaneous imbibition by considering slip effects in capillaries with nanoscale and built a spontaneous imbibition model by coupling the analytic equation based on fractal theory. In addition, Xiao et al ${ }^{18}$ derived an analytical model for the capillary pressure and water relative permeability in unsaturated porous rocks by taking into account the fractal distribution of pore size and tortuosity of capillaries. Integrating the fractal theory and molecular dynamics simulation, Liehui Zhang et al $\frac{19}{19}$ investigated the adsorption phenomenon in shale kerogen. In their work, the adsorption of methane in 2,5 and $10 \mathrm{~nm}$ slit-like pores was simulated at different temperatures and pressures, and the simulation results were analyzed using the multilayer fractal adsorption model. $\mathrm{Xu}$ and $\mathrm{Li}^{20}$ proposed a fractal model for erosion threshold of bentonite flocs, in which cohesion forces, the long-range van der Waals interaction between two clay particles are taken as the resource of the erosion threshold.

The fourth group of papers focuses on combining of fractal geometry and (rock) geophysical method in reservoirs. Using nuclear magnetic resonance (NMR) and mercury intrusion porosimetry (MIP), Fuyong Wang et al. ${ }^{[21}$ presented an advanced fractal analysis of the pore structures and petrophysical properties of the tight oil sandstones. The relationships between the fractal dimensions of different size pores calculated from NMR $\mathrm{T}_{2}$ spectrum and petrophysical properties of tight oil sandstones were analyzed. Micro-seismic diagnostic has been introduced into petroleum fields to describe the distribution of hydraulic fractures. Furthermore, Kai Zhang et al..$^{22]}$ integrated micro-seismic technology with history matching to predict the hydraulic fracture parameters. By considering the fractal feature of hydraulic fracture, a fractal fracture network model was established to evaluate this method in numerical experiment. Magnetotelluric was an electromagnetic-based exploration method, which has been widely used to identify the distribution of underground geoelectric structure. Jin Li et al.23] proposed a new technique for signal-noise identification and targeted de-noising of Magnetotelluric signals based on fractal-entropy and clustering algorithm. 


\section{CONCLUSIONS}

The use of fractal theory to characterize and model structure and transport properties of unconventional reservoirs is an extremely new field of research. Seventeen papers collected in this special issue focus on the characterization of pore (throat) structure, fractal network and crack propagation as well as its influences on physical properties of porous media, porous flow and gas adsorption mechanism, and modeling approaches by combining of fractal geometry and (rock) geophysical. The aim of the special issue is to further advance this multidisciplinary endeavor.

\section{ACKNOWLEDGMENTS}

The guest editors would like to acknowledge the authors for their inspiring contributions and the anonymous referees for their tremendous efforts. The first guest editor, Professor Cai, would like to thank the National Natural Science Foundation of China (41722403, 41572116) for supporting his series of studies on flow and transport in fractal porous media.

\section{REFERENCES}

1. B. B. Mandelbrot, The Fractal Geometry of Nature (W. H. Freeman, New York, 1982).

2. M. Sahimi, Flow phenomena in rocks: From continuum models to fractals, percolation, cellular automata, and simulated annealing, Rev. Mod. Phys. 65 (1993) 1393-1534.

3. B. M. Yu, Analysis of flow in fractal porous media, Appl. Mech. Rev. 61 (2008) 050801.

4. E. Perfect, Y. Pachepsky and M. A. Martin, Fractal and multifractal models applied to porous media, Vadose Zone J. 8 (2009) 174-176.

5. J. C. Cai, F. San José Martínez, M. A. Martín and E. Perfect, An introduction to modeling of flow and transport in fractal porous media: Part I, Fractals 22 (2014) 1402001.

6. J. C. Cai, F. San José Martínez, M. A. Martín and $\mathrm{X}$. Y. Hu, An introduction to flow and transport in fractal models of porous media: Part II, Fractals $\mathbf{2 3}$ (2015) 1502001.

7. H. Huang et al., Pore-throat structure and fractal characteristics of Shihezi Formation tight gas sandstone in the Ordos Basin, China, Fractals 26 (2018) 1840005 .

8. K. Li et al., Fractal characteristics of pores in Taiyuan formation shale from Hedong coal field, China, Fractals 26 (2018) 1840006.
9. Y. Wang et al., Morphology and fractal characterization of multiscale pore structures for organicrich lacustrine shale reservoirs, Fractals 26 (2018) 1840013.

10. J. Li et al., Fractal characteristics of continental shale pores and its significance to the occurrence of shale oil in China: A case study of Biyang Depression, Fractals 26 (2018) 1840008.

11. J. Liu, Y. Yao, D. Liu, Y. Cai and J. Cai, Comparison of pore fractal characteristics between marine and continental shales, Fractals 26 (2018) 1840016.

12. W. Wang et al., Fractal nature of porosity in volcanic tight reservoirs of the Santanghu basin and its relationship to pore formation processes, Fractals $\mathbf{2 6}$ (2018) 1840007.

13. W. Lin et al., A new improved threshold segmentation method for scanning images of reservoir rocks considering pore fractal characteristics, Fractals $\mathbf{2 6}$ (2018) 1840003.

14. N. Huang, Y. Jiang, R. Liu and Y. Xia, Size effect on the permeability and shear induced flow anisotropy of fractal rock fractures, Fractals 26 (2018) 1840001.

15. Y. Zhao, S. Gong, C. Zhang, Z. Zhang and Y. Jiang, Fractal characteristics of crack propagation in coal under impact loading, Fractals 26 (2018) 1840014.

16. G. Lei, S. Mo, Z. Dong, C. Wang and W. Li, Theoretical and experimental study on stress-dependency of oil-water relative permeability in fractal porous media, Fractals 26 (2018) 1840010.

17. Y. Shen, C. Li, H. Ge, X. Guo and S. Wang, Spontaneous imbibition process in micro-nano fractal capillaries considering slip flow, Fractals 26 (2018) 1840002.

18. B. Xiao et al., A fractal model for water flow through unsaturated porous rocks, Fractals $\mathbf{2 6}$ (2018) 1840015.

19. L. Zhang et al., Study on the adsorption phenomenon in shale with the combination of molecular dynamic simulation and fractal analysis, Fractals $\mathbf{2 6}$ (2018) 1840004.

20. Y. F. Xu and X. Y. Li, Fractal approach to erosion threshold of bentonites, Fractals 26 (2018) 1840012.

21. F. Wang, K. Yang and J. Cai, Fractal characterization of tight oil reservoir pore structure using nuclear magnetic resonance and mercury intrusion porosimetry, Fractals 26 (2018) 1840017.

22. K. Zhang et al., Parameter prediction of hydraulic fracture for tight reservoir based on micro-seismic and history matching, Fractals 26 (2018) 1840009.

23. J. Li et al., Signal-noise identification of magnetotelluric signals using fractal-entropy and clustering algorithm for targeted de-noising, Fractals 26 (2018) 1840011. 